This is an accepted manuscript of an article published by Wiley Online in International Migration on 19 January 2018, available online:

https://onlinelibrary.wiley.com/doi/abs/10.1111/imig.12426 


\title{
Migrant Health Policies. Actors and Levels in a Multi-Level Perspective
}

\author{
Roberta Perna - Consejo Superior de Investigaciones Científicas, Instituto de Políticas y Bienes \\ Públicos (CSIC-IPP), Madrid
}

\begin{abstract}
Until recently, migrant health policies have been overlooked as topic of policy analysis. Although interest on the issue has developed in parallel with the progressive acknowledgement of the presence of unhealthy migrants and the transformation of welfare states and policy dynamics in Europe, studies on migrant health policies have often focused on the state as unique unit of observation while hindering the role played by other institutional and non-institutional actors that take part in the migrant health multi-level governance. This contribution will bridge this gap, deconstructing the various actors and levels involved in migrant health policy making from a multi-level perspective. By critically reviewing migrant health policy research and discussing it with the new MIPEX Health Strand, this contribution suggests adopting a more encompassing perspective in the analysis of migrant health policies and processes, looking at the different players that are at stake in this multi-faced policy field.
\end{abstract}

\section{INTRODUCTION}

Over the last 20 years, the increasing inflow of migrants and their settlement in Europe have led governments to face the task of integration, including migrants' entitlement and access to healthcare. In this sense, health is strongly connected to integration, the two issues being reciprocally dependent (Ingleby et al., 2005: 101). Health problems hinder migrants' integration, reducing the possibilities for individuals to participate in the economic, social and political life of the destination country. Consequently, illness may lead to marginalisation, which in turn exacerbates illness. At the same time, integration is a prerequisite for effective healthcare delivery, which is often impeded by inadequate policies concerning migrants' entitlement and access to healthcare. Moreover, since healthcare systems constitute a central domain of European welfare states, their transformation is strongly intertwined with the issue of migrants' health, given that migration is considered as one of the challenging factors of social protection in Europe. Therefore, academic interest in migrant health policies has developed in parallel with the progressive development of national measures to deal with migrants' health status.

In fact, until the 1980s academic literature on migrants' health has mainly focused on migrants' health status from an epidemiological perspective and, thus, it has been carried out primarily by public health scholars. On the contrary, migration and policy studies paid less attention to this field and, when involved, they mainly focused on the national level of policymaking. By critically reviewing the existing state of art on migrant health policies and discussing it with the recent MIPEX Health Strand data (OIM, 2016), this article suggests exploring migrant health policies and processes from a more encompassing, multi-level analytical perspective. To this extent, this contribution first presents and critically reviews the genesis and transformations of migrant health research, identifying three branches of studies on the issue. Then, it specifically addresses the 
topic of migrant health policymaking, delineating a multi-level analytical framework to identify the plurality of relevant institutional and non-institutional actors involved in this field and their relations.

\section{GENESIS AND EVOLUTION OF THE FIELD}

By following the evolution of migrant health research, three branches of studies can be identified. The first one, centred on public health and ethnomedicine, dominated the debate until the 1970s and it was concerned with issues of health security and the 'exotic' nature of migrants' diseases. The second branch, developed since the 1980s, has focused on the determinants of migrants' health, widening the focus to all factors influencing migrants' health during all stages of the migration process, whereas the third and more recent field of research has paid specific attention to policies, focusing on similarities and differences in migrant health policies across Europe.

\section{The Trente Glorieuses. The domination of health studies}

During the Trente Glorieuses (1945-1975) and in the period of institutionalisation of the Keynesian National Welfare State (KNWS), European countries largely neglected the presence of migrants, and welfare policies were directed towards the needs of (alleged) ethnically homogenous populations. As Jessop affirms (1999: 350), the KNWS "was national in so far as economic and social policies were pursued within the historically specific (and socially constricted) matrix of a national economy, a national state, and a society seen as comprising national citizens" (emphasis in the original text). Hence, the issue of migrants' health was merely tackled as a problem of border control through measures aimed at controlling infectious diseases such as yellow fever, tuberculosis, and cholera (Hayes, 2000). Moreover, immigration policies aimed at selecting healthy "birds of passage" (Piore, 1979), entitled to limited social rights as they were expected to return to their native countries after becoming useless for the European labour markets (Hemerijck et al. 2013).

After the 1973 oil crisis, massive industrial restructuring and unemployment took place in several European countries. Many low-skilled migrant workers lost their jobs but, against expectations, most of them did not repatriate to their native countries. Rather, "Seeing the door to future mobility closed, migrants decided to stay on" (Schierup et al., 2006: 38). Nevertheless, the framing of migrants' health integration did not change in that period: it was still regarded as a straight-line process of assimilation, and problems associated to everyday life - including healthrelated ones - were assumed to be resolved automatically throughout migrants' stay (Cattacin et al., 2009).

In that environment, scholarly interest for migrants' health was confined to certain disciplines, namely public health and ethnomedicine. Until the end of the 1970s, public health research mainly addressed issues such as health security and risks of contagious illness that were potentially introduced through migration. Concerned with the "pathological baggage" of immigrants, public health studies focused on risk groups that could pose a threat to public health security (Gentilini et al., 1986). Although nowadays, public health research has partially shifted its focus of analysis, developing several studies on migrants' health status, they still focus on health and disease patterns of migrant groups compared to the ones of the population in destination countries with a strong epidemiological perspective (McKay et al., 2003). 
Similarly, tropical medicine, ethnomedicine and ethnopsychiatry were interested in the biological, genetic and cultural determinants of migrants' health, building their research on the individual as unit of analysis. As their basic assumption was that "non-white" individuals radically differ from "whites", analysis was developed through the categories of race, focusing on the "exotic" nature of migrants' diseases and their extra-ordinary behaviours (Ingleby et al., 2005). Apart from the colonial and racialist assumptions that gave origin to this branch of research, the limitations of such an approach are evident. These disciplines considered migrants' health as static, assuming that local disease patterns in the country of origin and the ethnic and cultural background of migrants would have determined in a straight-line way individuals' health status. Furthermore, these disciplines usually focused on individual patients and their conditions of illness, without considering how other factors beyond individual characteristics may influence migrants' health.

\section{The 1980s as a turning point. The determinants of migrants' health}

Since the 1980s, the growing "super-diversity" of migrant populations in Europe (Vertovec, 2007) and the increasing presence of "unhealthy" and "exhausted migrants" (Bollini and Siem, 1995) have fostered research to thoroughly address migrants' health. Studies have devoted attention to a large set of factors that may have a cumulative effect on migrants' health throughout different stages of the migration process, namely:

1. Pre-departure. Good health is usually a decisive factor of the migration project. During this stage, biological and genetic characteristics as well as the exposure to local disease patterns and other environmental factors influence individual health. Moreover, ethnic and cultural backgrounds may embed risky behaviours (e.g. practices of genital mutilation) or healthy habits (e.g. Muslim proscription on consuming alcohol). In addition to individual determinants, the country of origin's healthcare system and political environment are fundamental factors that influence migrants' health (Gushulak and MacPherson, 2011).

2. Travel phase. During this phase, migrants may stop in multiple transit locations for short or long periods of time, thus being exposed to health risks because of disease prevalence in those zones and circumstances of travels (Lynch and Roper, 2011). Furthermore, during this stage kidnapping or sexual violence might affect migrants' physical, mental and psychological health (Zimmerman et al., 2011).

3. Destination phase. Voluntary migrants usually have better health than the native-born population, reflecting a selection bias in migration known as the "healthy migrant effect" (Lassetter and Callister 2009) ${ }^{1}$. However, soon after migrants arrive at a destination country, this positive health status may begin to deteriorate to levels similar or even worse to those of the native-born population because of different factors, which include: a) exposure in the destination country to new diseases against which recent migrants are not immunised; $b$ ) acculturation to risky lifestyle, behaviours and habits (ibid.); c) poor employment and living conditions in destination countries and uprooting (Bolzman, 2002; Bhugra, 2004); $d$ ) restrictive immigration and integration policies as well as levels of entitlement to the destination country's healthcare system and degree of accessibility, availability, usability and quality of its services (Torres-Cantero et al., 2007); e) direct and indirect racism and discrimination (Nazroo, 2003).

4. Interception phase. This phase, which applies particularly to undocumented migrants (UMs) and asylum seekers, is characterised by situations of temporary detention that are usually established by national, bi-lateral, international or supranational policies on immigration and 
border control. Temporary detention centres and/or refugee camps can have detrimental consequences on migrants' mental and physical health. Moreover, they are often characterised by unhygienic and unsafe conditions (Steel et al., 2011).

5. Return phase. When migrants go temporarily back to their country of origin or decide to resettle, they may face difficulties in finding adequate or affordable healthcare. Moreover, psychological problems may derive from the re-settlement process in contexts in which migrants have lost their previous social networks because of having migrated (Davies et al., 2011).

This encompassing framework demonstrates how, in recent years, the issue of migrant's health has been tackled in a more accurate way. Nevertheless, research still tends to reduce these determinants to the sole "socio-economic" determinants, ignoring the role of other factors in the creation of inequities, including its institutional determinants (for a critical review, see: Ingleby, 2012).

\section{A third field of studies. Approaching migrants' health through policies}

In the last two decades, migrants' health has become a specific policy field over which research has started to take shape to understand similarities and differences in migrant health policies across European countries. Overall, these studies highlight that migrant health policies are usually more developed in countries where immigration is a structural phenomenon and immigrants represent a relevant percentage of the total population. On the contrary, less interest is put on this issue by the governments of countries in which immigration is a comparatively recent phenomenon and the percentage of immigrants is relatively small (Fernandes et al., 2009).

Moreover, the way migrants' health is addressed seems to depend on the groups that are more salient in a country. In most Northern European countries, where immigration has largely consisted of refugees and asylum seekers, discussions about migrants' health mainly concern mental and psychological health, and the concept of "traumatisation" is predominant (Ingleby et al., 2012). In the Netherlands, traditionally represented as "the country of multiculturalism", interventions have mainly addressed cultural differences (Ingleby et al., 2005), while in the United Kingdom, which has substantial ex-colonial immigration, policies have been mainly concerned with racism and its effect on migrants' health (Jayaweera, 2010). In Italy and Spain, countries of immigration since the late 1980s and with a relevant percentage of UMs, slight attention has been paid to cultural accommodation. However, these countries have adopted inclusive health policies that entitle also UMs to more than emergency care (Vázquez et al., 2011).

Some of these studies have also investigated the ways in which different health regimes result in different degrees of migrants' entitlement to and coverage by healthcare systems (Cattacin et al., 2009; Scuto, 2011). Accordingly, National Health Systems (NHSs) - which guarantee access to all people regularly residing in a country with a tax-based financing system - usually develop more inclusive migrant health policies given that they guarantee access to healthcare on the basis of regular residence. For this same reason, they may limit the possibility of accessing health services for non-residents or UMs. At the opposite, Insurance Health Systems (IHSs) may not formally impede migrants' access to health services, as they subordinate access to healthcare on the payment of an insurance premium. However, this payment may constitute an exclusionary criterion from healthcare insomuch it has a particularly harmful effect on vulnerable groups of migrants, such as UMs and asylum seekers. 
Finally, research tends to show that a relationship exists between migrant health policies and each country's immigration history and prevailing approach to diversity (Cattacin et al., 2007, 2009; Vázquez et al., 2011). These studies consider that in countries traditionally orientated to "assimilation", people are treated equal in terms of rights and duties, without taking into account differences in countries of origins or cultural backgrounds. Consequently, specific measures in national policies are avoided also in the field of healthcare. On the contrary, in countries where ethnic and religious groups have traditionally been recognised as a structural feature of the society, the institutionalisation of cultural diversity is present also in migrant health policies, which promote specific interventions for migrants and ethnic minorities.

Beyond descriptive analysis, however, these classifications seem to be strongly influenced by a tradition of research in migration studies known as the "regime paradigm" that treats issues of migration and citizenship according to consistent and distinct national models (among others, see: Brubaker, 1992; Hollifield, 1997; Joppke, 1999). Consequently, they present three fundamental weaknesses. First, they take as point of departure the a-priori assumption of a difference between countries, thus hindering the identification of similar outcomes or processes across states. On the contrary, several empirical studies emphasise the tendency of European countries to converge in their policies concerning migration on various issues (among others, see: Favell, 1998; Penninx et al., 2004). Given that since the 2000s an international framework on migrants' health has started to take shape, promoted by several international organizations and - to a lesser extent - the European Union, the acknowledgment of this first weakness may prove to be relevant in migrant health policy studies.

Second, these studies assume the nation-state as the main unit of observation. To confront the "regime paradigm"'s state-centred perspective, many studies have highlighted the role of subnational levels in challenging national policies, philosophies and approaches (Caponio and Borkert 2010). In migrant health policy studies, however, this weakness has been questioned only in recent times, as it will be presented in the following section. Finally, research on migrant health policies often pay less attention to the phase of policy implementation, considering the policymaking process as hierarchical, linear and rational, and thus following a top-down pattern, from policy decisions to implementation. Yet, focusing only on formal policies may hinder the discrepancies that exist between decisions and rules 'on the book' and daily practices of healthcare at the frontline of each country's healthcare system. In fact, while governments have the power to define specific migrant categories and their associated degrees of eligibility to healthcare protection (Sainsbury 2006), the concrete responsibility to draw a line between those who should deserve access to healthcare and whose who should not is in the hands of "street-level bureaucrats" (Lipsky 1980; Willen 2012).

As it becomes clear from this systematisation, a multi-level approach to migrant health policies and policymaking processes appears fundamental to identify the totality of relevant actors involved and their relations, as well as the interconnections that exist between policy fields and that influence the definition and implementation of migrant health policies in Europe.

\section{A MULTI-LEVEL FRAMEWORK. ACTORS AND LEVELS IN MIGRANT HEALTH POLICY MAKING}

Migrant health policies may be defined as specific courses of actions adopted and pursued by a government or other organizations to improve migrants' health. By setting priorities and 
interventions, they address the institutional, organizational and individual determinants that positively or negatively influence migrants' health status

These decisions are thus the result of the involvement of a "constellation of actors", both governmental and non-governmental, whose weight may vary over time and across territories (Zincone et al., 2011). Consequently, different actors at different levels have to be considered when analysing migrant health policymaking, opening the field to the analytical lenses of multi-level governance (MLG) to highlight how "authority and policymaking influence are shared across multiple levels of governments - subnational, national, and supranational" (Marks et al., 1996: 342). This means that, whereas central governments remain important, policymaking competences are shared by actors at different levels. From this perspective, “'[m] ulti-level' refer to the increased interdependence of governments operating at different territorial levels, while 'governance' signal the growing interdependence between governments and non-governmental actors at various territorial levels" (Bache and Flinders, 2004: 3, quoted in Piattoni, 2010: 83).

Therefore, tree main dimensions have to be considered in the analysis of migrant health policymaking from a MLG perspective, namely: (1) the different levels of institutional and (2) noninstitutional actors that are simultaneously involved; and (3) the interrelationships that are created among them, either more top-down or bottom-up orientated (Zincone et al., 2011). Figure 1 summarizes this plurality of actors that may be involved in the main 'phases' of an ideal policy cycle in various moments and for different purposes.

Figure 1. Main actors in the healthcare-migration policy cycle

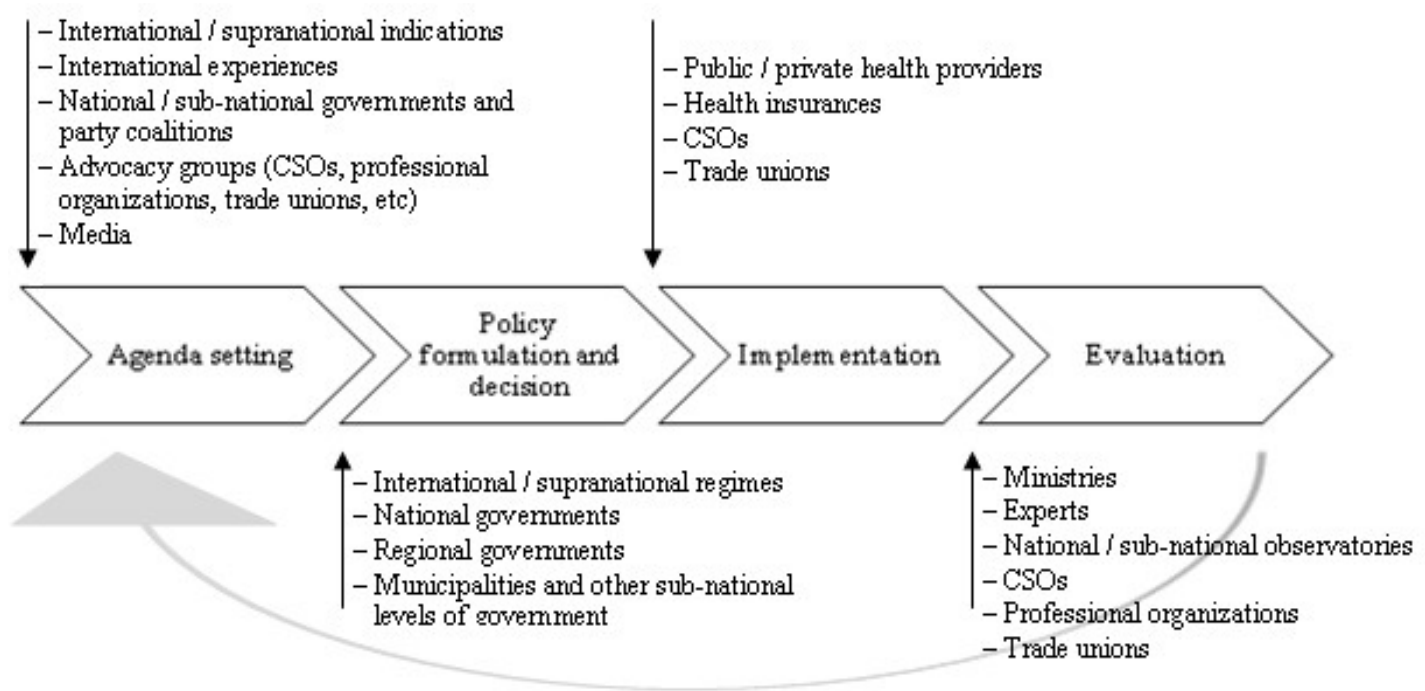

\section{Institutional actors}

The international ambience, composed by international organizations and the EU, represents a first element to consider in the analysis of migrant health policymaking. Over time, international obligations and recommendations, as well as EU initiatives and deliberations have become an important source of top-down pressure for policymakers, fostering a homogeneous framework on migrant' health across Europe. Although these policy tools are often non-binding for nation-states and despite the fact that migrants' health is hardly a EU policy as it hovers between spontaneous and steered coordination interventions, these actors have increased their steering power on national and subnational governments through technical advice tools as a form of 'friendly persuasion'. 
This is for instance the case of the World Health Organization's Resolutions ${ }^{2}$, the International Organization for Migration (OIM)'s interventions ${ }^{3}$ and the EU Council's Conclusions $^{4}$. Nowadays, of particular importance is the 2011 Council of Europe's Recommendation on Mobility, Migration and Access to Healthcare. Arranging previous interventions on the issue of migrants' health into a coherent and systematic framework, the Recommendation represents a relevant reference point for both policymakers and scholars on migrant health policies. Built around six broad dimensions ${ }^{5}$, it has been adopted as the starting normative framework to develop, for the first time in 2015, the Migrant Integration Policy Index (MIPEX) Health Strand, which compares governments' interventions in EU countries and other states on migrants' health on four dimensions: migrants' entitlement to healthcare, policies to promote access, responsive health services, and measures to promote change ${ }^{6}$.

By looking at the MIPEX Health Strand results (OIM, 2016), one of its most interesting findings is that whether a country belongs to the EU15 or the post-2000 accession countries is a strong predictor of Health Strand scores. Accordingly, almost all EU15 countries gained high scores as they guarantee almost unconditional inclusion to healthcare for migrants who are present in the country on a regular basis and for asylum seekers, regardless of the type of their healthcare regime (either NHS or IHS). Predictably enough, EU15 states represent countries in which immigration is a structural phenomenon, as found in some studies mentioned before. Indeed, traditional countries of immigration like France, the Netherlands, the UK and Belgium usually guarantee access to healthcare for migrants who are present on a regular basis.

The same is true for Northern EU countries, which have been traditionally considered the quintessential of Esping-Andersen's social-democratic welfare regime and enjoyed the reputation of having one of the world's most far-sighted immigration policies until a few years ago (Schierup et al., 2006). In these countries, however, UMs were totally neglected from the national legislation until the beginning of the 2010s, when they started to 'appear' as rejected asylum seekers. Therefore, health policies for UMs have been barely developed, leaving large room for manoeuvre to health providers who play the role of gatekeepers of these healthcare systems (Biffl and Altenburg, 2012).

At the opposite, in Southern European countries - characterised by the lack of a coherent management of immigration until the end of 1990s and a high quota of UMs among the migrant population - UMs' access to healthcare has been guaranteed to more than a minimum level. Nevertheless, since the 2008 economic crisis and the following austerity measures imposed on these countries, several restrictions have been introduced on migrants' access to healthcare. In Portugal and Spain, for instance, traditionally inclusive entitlements and exemptions in law have been undermined by restrictive reforms, problems of documentation and discretion, especially hindering UMs and asylum seekers' access to healthcare.

On the contrary, post-2000 accession countries scored lower in the MIPEX Health Strand ranking, as the most of them define entitlement to healthcare services in relation to migrants' employment status and include some conditions for inclusion concerning asylum seekers, such as means tests or requirements of compulsory stay in centres in which asylum seekers are hosted. Post2000 accession countries are mainly Central and Eastern EU countries, which nowadays are sending, transit and new destination countries of migration at the same time. Hence, there is still a lack of coherent and specific policy frameworks on migrants' health, due to their relatively new history of immigration and their recent access to the EU. Nevertheless, most of them represent the 
current Eastern border of the EU, thus having to directly face the so-called 'refugee crisis' and asylum seekers' health needs with insufficient tools. Moreover, the impact of restrictive economic interventions on migrant health policies has been relevant in some of these countries as well: for instance, in Slovenia and Cyprus means test threshold for entitlement have been raised, while in Latvia the basis for entitlement has been changed from residence to insurance status (Thomson, 2014)

Yet at the same time, when it comes to the definition and implementation of measures to promote migrants' access to healthcare and migrant-friendly reforms, the MIPEX Health Strand results suggest that these measures are more widespread in NHSs, with the central government issuing action plans, directives and programmes on these issues, than in IHSs, in which local players enjoy more autonomy in the field. Hence, the concrete weight of central governments depends on each country's healthcare governance structure. Specifically, the way the health system is structured and financed (tax-based, insurance-based or a mix between the two), the distribution of competences and resources across public and private health actors (distinguishing between decision-makers, funders and providers) and the organization of health services across the territory (national, regional and/or local) strongly influence the migrant health policymaking process and its outcomes.

In fact, along with top-down influences from the institutional ambience, bottom-up pressures to national policies come from regional and local governments, as these actors have gained a high degree of autonomy in the domain of healthcare since the late 1970s (Saltman, 2008). To date, regional authorities enjoy important power concerning the definition of territory-specific health programmes and interventions in countries as such Belgium, Czech Republic, Italy, Spain and Sweden. At an even lower level, provincial and local authorities are central in health planning in Austria, Denmark, the UK, Finland and the Netherlands (European Union - Committee of the Regions, 2012). Nevertheless, when it comes to migrant health policies, attention to the subnational dimension of decision-making is still poor. Few studies have highlighted the importance of considering regional and local governmental actors in this policy field (Geraci et al., 2010; Merotta, 2011; Moreno Fuentes, 2015). These particularly focus on two countries, namely Italy and Spain, given the traditional attention of scholars on the territorial heterogeneity of these countries on issues concerning health and social policies.

For what concerns Spain, for instance, until 2012 all people living in the country were entitled to its NHS on equal grounds. Access to healthcare did not depend on legal residentship, meaning that Spain had the most inclusive health policy framework for UMs in Europe (Scuto, 2011). Nevertheless, in 2012, the central government attempted to restrict UMs' entitlement to healthcare by Real Decreto 16/2012, removing health cards to UMs older than 18 and only guaranteeing their access to emergency care. These measures, introduced to cut public health spending, were publicly presented as tools to contrast the (alleged) abuse of the healthcare system by "health tourists" (Moreno Fuentes, 2015: 284-285). However, only few regional governments applied the Royal Decree rigorously, while six Comunidades Autónomas formally opposed it against the Constitutional Court, basing the appeals against either a violation of the constitutional right to health (in the case of Navarra only) or central government's interference in regional competences. Moreover, several regional governments passed legislations on UMs' access to healthcare to block, or at least reduce, the impact of the 2012 national law. Therefore, due to the uneven application of the Real Decreto across the country and thanks to widespread protests coming from civil society 
organizations (CSOs), international organizations and health professional associations, since March 2015 UMs' entitlement to healthcare has been re-extended, although with a more limited coverage than before.

The same degree of regional variation may be found concerning the provision of healthcare to UMs in Italy. 1998 Immigration Law affirms that each Region has to identify the most appropriate ways to guarantee access to 'urgent and essential care' for UMs, which can be provided by public or accredited private hospitals and in collaboration with non-governmental organizations and voluntary associations. As a result of this institutionalised room for maneuver, in 2010 targeted health departments providing health services to UMs existed in four regions (Emilia-Romagna, Tuscany, Lazio and Piedmont), while in Lombardy, Basilicata and Calabria UMs could access public emergency rooms mainly for urgent care, formally or informally charging NGOs to guarantee healthcare to UMs (Geraci et al., 2010; Pasini, 2011). More generally, regional migrant health policies and interventions highly differ across the countries, which may be placed along a continuum that goes from highly inclusive and responsive health policies (in regions such as Emilia-Romagna, Tuscany and Umbria, in the North-Centre of Italy); to inclusive but not responsive health policies, which guarantee access to healthcare while tend to hinder migrants' 'diversity' (such as in Lombardy and Veneto, in the North of Italy); to residual migrant health policies, which pay few attention to the migrant population and its health needs and demands (like in Campania and Basilicata, in the South of the country) (Author 2016).

As it clearly emerges from these two countries, sub-national governments may challenge national policies at various degrees, leading to heterogeneous degrees of migrants' accessibility to healthcare but also to inequalities among the migrant population within the boundaries of a same country.

\section{Non-institutional actors and policy implementation}

Next to institutional actors, non-governmental players are fundamental in influencing and shaping migrant health policymaking at all levels, including experts and media, CSOs and health providers.

With respect to experts and knowledge, recent studies on the research-migration policy nexus (Scholten et al., 2015) highlight that experts may play a relevant role in influencing and steering policymaking, either by encouraging governments to adopt more inclusive policies or sustaining/contrasting the supposed "welfare magnet hypothesis" ${ }^{7}$. Being part of specific "discourse coalitions" (Duyvendak and Scholten, 2011), these actors may influence policymaking from 'outside', through academic debate and conferences, and from 'inside', when they are involved in the agenda setting, problem-definition and policy evaluation. More generally, the role of knowledge and its use should not be neglected in the analysis of migrant health policymaking, given that in recent years relevant partnerships have been built between cities, health organizations and experts searching for knowledge and resources. Several horizontal partnerships have been promoted, in particular by the European Commission, which has encouraged programmes and best practices exchange as well as research networks among cities, health practitioners, organizations and experts ${ }^{8}$.

Likewise, media can contribute to give visibility to a problem by alerting, sensitising and mobilising the public opinion on issues related to migrants' health. At the same time, however, it 
can diffuse sensationalistic images concerning migrants' health, describing migration as a threat to public health security. Media often give simplistic representations of the reality (Esses et al., 2013), evoking dangerous associations between migrants and public health risks by depicting them as 'dirty', 'ill' and 'likely to spread diseases' (Barretta, 2015), and thus they foster emergency interventions rather than structural responses to migrants' health.

As far as CSOs are concerned, they often constitute an active advocacy coalition for the promotion of migrants' right to healthcare (Ambrosini and van der Leun, 2015). Similarly, trade unions are often involved in political actions for migrants' rights and in the provision of services (Marino 2013). Ranging from international non-governmental organizations concerned with migration, healthcare and human rights (e.g. Médicins du monde, Médicins sans frontiers, HUMA, PICUM) to local voluntary associations and migrant organizations, these actors may play a crucial role in the policy arena, advocating and/or campaigning for migrants' right to healthcare. Moreover, they can limit or counterbalance non-inclusive health policies, filling in the gaps left open by the state (van der Leun, 2003). By directly providing health services to excluded groups of migrants, they often react to the "institutional de-responsibility" (Pasini, 2011: 27) of political actors who formally or informally avoid providing healthcare services to non-native populations.

Finally, health providers and health insurances (particularly in IHSs) represent a crucial, yet often neglected category of migrant health policymakers. In cooperation with CSOs and trade unions, "committed providers" (Marrow, 2012) may exercise strong pressures 'from inside' the healthcare system against restrictive policies, urging governments to adopt more inclusive and effective policy actions concerned with migrants' health (Zincone, 1998; Ambrosini, 2015). Furthermore, health providers are de facto policymakers insomuch they often reframe, by-pass and even modify restrictive health policies, adopting "benevolent contra legem practices" (Zincone, 1998: 45) to informally guarantee migrants' access to healthcare. Accordingly, Dauvrin and colleagues (2012) describe a process of de facto convergence across European countries concerning UMs notwithstanding different countries' policy framework, affirming that, thanks to "a deep rooting of humanism in the minds of pragmatic health professionals" (Dauvrin et al., 2012: 6), health providers in Europe tend to adopt similar ethical-orientated discretionary practices, opening the access to healthcare for UMs. This is because, as they stressed in a previous research (Devillé et al. 2011), broad consensus exists among health experts and practitioners across European countries regarding some fundamental ethical and professional principles, such as universal access to healthcare resources and treatments, culturally sensitive healthcare services, empathy and nondiscrimination.

Nevertheless, health providers are not necessarily migrant-friendly, and discretionary practices may not be benevolent per se (Author 2017). According to the OIM (2016)'s Summary Report on the MIPEX Health Strand, migrants' access to healthcare is severely affected by the use of discretion, which is often the consequence of ambiguous policies and definitions (such as the concepts of 'urgent' or 'essential care') that may leave room for potentially different interpretations. It reports that health workers and organizations often use their room for manoeuvre when they carry out administrative procedures, draw clinical conclusions and assess a person's financial need, therefore jeopardising migrants' formal entitlements to healthcare. Particularly, the Report highlights that discretional decisions are significantly frequent for UMs, for which the predictability of coverage is undermined by discretional decisions in no less than 30 out of 34 countries considered by the OIM survey, namely: Austria, Belgium, Bahrain, Bulgaria, Croatia, Cyprus, 
Czech Republic, Denmark, Estonia, Finland, Germany, Greece, Hungary, Iceland, Ireland, Italy, Latvia, Lithuania, Macedonia, Malta, the Netherlands, Norway, Poland, Romania, Slovakia, Slovenia, Spain, Sweden and the United Kingdom (ivi, p. 49). As a result of this, countries reporting the same level of UMs' formal entitlement to healthcare, such as Sweden, Italy, Romania and Belgium, obtained very different global 'entitlement score' in the MIPEX Health Strand due to the effects of administrative discretion and barriers. ${ }^{9}$

Therefore, if from a 'simple' numerical point of view, it seems to be relevant to analyse discretion in the implementation of healthcare policies, from a policy perspective it is an unmet challenge as migrants' concrete access to healthcare services ultimately depends on street-level decisions.

\section{CONCLUDING REMARKS}

Until the late 1980s, migrant health policies have been overlooked as specific topic of policy analysis. Throughout the twentieth century, health and immigration policies were perceived by central governments as fields of their exclusive competence and over which they jealously guarded their sovereignty. Nevertheless, changes in immigration dynamics as well as challenges to national welfare states have opened the door to a multiplication of institutional and non-institutional actors over time, which act at different territorial and functional levels than the unique national one.

Despite this complexification in policymaking dynamics, until recently migrant health policy studies have usually focused on the national level, assuming that the framework defined by a central government will account for the specific way in which a country addresses issues of migration and healthcare, and thus looking for national models or regimes. However, this approach presupposes the centrality of national governments in migrant health policymaking, hindering the role of those supranational and sub-national actors that are also part of the multi-level governance of migrants' health.

By critically reviewing the existing state of art on migrant health policies and discussing it with the recent MIPEX Health Strand data (OIM, 2016), this article suggests to move towards a more encompassing analytical, multi-level perspective to migrant health policies and processes. From this view, decisions concerning migrants' health should be interpreted as the result of the involvement of a constellation of institutional and non-institutional actors, whose weight and relations may vary over time and across territories. In addition, these actors' perspectives and aims may differ and even contrast, making migrant health policies a contested arena in which different players are at stake. By adopting a multi-level perspective, research should identify the relations and interactions that exist between these plural and dynamic actors to better grasp the complexities that weave together issues of health and migration in a contemporary Europe of political, economic and humanitarian crises.

\section{NOTES}

1. Nevertheless, recent studies have detected that people migrating for family reunions or seeking asylum are less 'healthy' than voluntary migrants, thus questioning the current validity of the "healthy migrant effect" (Domnich et al. 2012).

2. Among the most relevant, see: WHO (2008), Health of Migrants. Resolution $61.17,61^{\text {st }}$ World Health Assembly, 24 May 2008, Geneva, available at http://apps.who.int/iris/bitstream/10665/23533/1/A61_R17-en.pdf; WHO (2008), Closing the Gap in a Generation. Health equity through action on the social determinants of health, Geneva, available at 
http://tinyurl.com/nuypbda; WHO (2009), Reducing Health Inequities through Action on the Social Determinants of Health. Resolution 62.14, 62 ${ }^{\text {nd }}$ World Health Assembly, 22 May 2009, Geneva, available at http://tinyurl.com/oq2mvb; WHO and OIM (2010), Health of Migrants - The Way Forward. Report of a Global Consultation, Geneva, available at http://tinyurl.com/p9hgr5e.

3. See, in particular, the "EQUI-HEALTH Project", available at http://equi-health.eea.iom.int/.

4. Among the most relevant, see: Council of the EU (2006), Council Conclusions on Health in All Policies, Brussels, available at http://tinyurl.com/p77foy2; Council of the EU (2007), Council Conclusions on Health and Migration in the EU, Brussels, available at http://tinyurl.com/3akvfzp; Council of the EU (2010), Council Conclusions on Equity and Health in All Policies: Solidarity in Health, Brussels, available at http://tinyurl.com/32tajqy.

5. These dimensions include: 1) knowledge about migrants and their situation; 2) migrants' health status; 3 ) entitlement to health service provision; 4) accessibility to the health system; 5) quality of health services; and 6) general measures to promote change.

6. For more information on the MIPEX Health Strand, see http://www.mipex.eu/health and IOM (2016).

7. The "welfare magnet hypothesis" argues for the existence of a 'magnet effect' by which generous welfare systems attract migrants from abroad. Nevertheless, empirical evidence found no relation between migration and welfare generosity, highlighting how factors such as income, migratory chains and networks are actually the major determinants of migration dynamics (Giulietti and Wahba 2012).

8. Among others, see: The Migrant Friendly Hospitals Project, available at http://www.mfheu.net/public/home.htm; MigHealth Project, an information network on good practices on healthcare for migrants and minority groups in Europe, available at http://mighealth.net/; Healthcare in NoWhereLand, a survey of best practices for improving UMs' entitlement and access to healthcare, available at http://www.nowhereland.info/. Moreover, the European Commission has subsidised two COST Actions concerning migrants' health: ISCH COST Action IS0603 - Health and Social Care for Migrants and Ethnic Minorities in Europe (HOME) (2007-2011), available at http://tinyurl.com/okke5q4, and ISCH COST Action IS1103 - Adapting European health systems to diversity (ADAPT) (2011-2016), available at http://tinyurl.com/ognb5bn.

9. It should be acknowledged that MIPEX and its indicators focus on formal policies defined at the national and regional levels, although they provide some information concerning the phase of policy implementation.

\section{REFERENCES}

Ambrosini, M.

2015 "NGOs and Health Services for Irregular Immigrants in Italy: When the Protection of Human Rights Challenges the Laws", Journal of Immigrant \& Refugee Studies, 13(2): 116134.

Ambrosini, M., J. van der Leun

2015 "Introduction to the Special Issue: Implementing Human Rights. Civil Society and Migration Policies”, Journal of Immigrant \& Refugee Studies, 13(2): 103-115.

Barretta, P.

2015 Notizie di Confine. Terzo Rapporto Carta di Roma 2015, Associazione Carta di Roma: Roma.

Bhugra, D.

2004 "Migration and mental health", Acta Psychiatrica Scandinavica, 109(4): 243-258.

Biffl, G., Altenburg F. (Eds.)

2012 Migration and Health in Nowhereland. Access of Undocumented Migrants to Work and Healthcare in Europe, Final Report of the Project "NowHerecare - Healthcare in 
NowHereland - Improving Services for Undocumented Migrants in the EU", Bad Vöslau: Theiss GmbH. Available at http://tinyurl.com/h9795rb. (Accessed 10 February 10 2016).

Bollini, P., H. Siem

1995 "No real progress towards equity: Health of migrants and ethnic minorities on the eve of the year 2000", Social Science \& Medicine, 41(6): 819-828.

Bolzman, C.

2002 "The Social Impact of Migration Policies: the Example of Immigrant Workers and Asylum Seekers in Switzerland", Social Work in Europe, 9(3): 10-19.

Brubaker, R.

1992 Citizenship and Nationhood in France and Germany, Harvard University Press, Cambridge.

Caponio T., M. Borkert (Eds.)

2010 The Local Dimension of Migration Policymaking, IMISCOE Reports, Amsterdam University Press: Amsterdam.

Cattacin, S., M. Chimienti, C. Björngren Cuadra (Eds.)

2007 Difference sensitivity in the field of migration and health. National policies compared, University of Geneva, Genève.

Cattacin, S., M. Chimienti, M.H. Alaoui (Eds.)

2009 Politique de migration et politique de santé en Europe. Des normes aux pratiques, Rapport de recherche, Université de Genève et Centre Maurice Halbwachs, Genève.

Council of Europe

2011 Recommendation CM/Rec (2011)13 of the Committee of Ministers to member states on Mobility, migration and access to health care. Strasbourg, 2011. Available at: https://search.coe.int/cm/Pages/result_details.aspx?ObjectID=09000016805cbd6d.

(Accessed on 4 April 2017).

Dauvrin, M., V. Lorant, S. Sandhu, et al.

2012 "Health care for irregular migrants: pragmatism across Europe. A qualitative study", BMC Research Notes 2012, 5:99.

Davies, A.A., R.M. Borland, C. Blake, et al.

2011 "The Dynamics of Health and Return Migration", PLoS Med, 8(6): e1001046.

Devillé, W., T. Greacen, M. Bogic, et al.

2011 "Health care for immigrants in Europe: Is there still consensus among country experts about principles of good practice? A Delphi study", BMC Public Health 2011, 11: 699.

Domnich, A., D. Panatto, R. Gasparini, et al.

2012 "The 'healthy immigrant' effect: does it exist in Europe today?", Italian Journal of Public Health, 9(3): e7532.1- e7532.7

Duyvendak J.W., P.W.A. Sholten

2010 "Beyond the Dutch "Multicultural Model". The Coproduction of Integration Policy Frames in The Netherlands", Migration \& Integration, 12(3): 331-348.

Esses, V. M., S. Median, A. S. Lawson

2013 "Uncertainty, Threat, and the Role of the Media in Promoting the Dehumanization of Immigrants and Refugees", Journal of Social Issues, 69: 518-536.

European Union - Committee of the Regions

2012 The management of health systems in the EU Member States - The role of local and regional authorities, written by Rogress Consulting S.r.l. and Living Prospects Ltd, available at http://tinyurl.com/guukz5e (Accessed 15 January 2016).

Favell, A.

1998 Philosophies of Integration: Immigration and the idea of citizenship in France and Britain, Macmillan/Centre for Research in Ethnic Relations, University of Warwick, Basingstoke. 
Fernandes, A., J. Pereira Miguel (Eds.)

2009 Health and Migration in the European Union: Better Health for All in an Inclusive Society. Final Report. International Organization for Migration, Brussels: 23-32. Available at http://tinyurl.com/2v8v8ph (Accessed 4 April 2017).

Ferrera, M.

2008 "From Welfare State to Welfare Regions: The Spatial Reconfiguration of Welfare in Europe", Italian Journal of Social Policy, 3/2008: 17-49.

Gentilini, M., G. Brücker, R. de Montvalon

1986 La santé des migrants, La Documentation française, Paris.

Geraci, S., M. Bonciani M., B. Martinelli

$2010 \quad$ La tutela della salute degli immigrati nelle politiche locali, Inprinting: Roma.

Giulietti, C., J. Wahba

2012 Welfare migration. Discussion Paper No. 6450, March 2012, IZA: Bonn.

Gushulak, B.D., D.W. MacPherson

2011 "Health Aspects of the Pre-Departure Phase of Migration", PLoS Med, 8(5): e1001035.

Hayes, D.

2000 "Outsiders within: the role of welfare in the internal control of immigration", in J. Batsleer and B. Humphries (Eds.) Welfare, Exclusion and Political Agency, Routledge, London, 6378.

Hemerijck, A.C., T.P. Palm, E. Entenmann, et al.

2013 Changing European Welfare States and the Evolution of Migrant Incorporation Regimes.

Background paper reviewing welfare state structures and reform dynamics in a comparative perspective, IMPACIM, VU University Amsterdam, Amsterdam.

Hollifield, J.F.

1997 L'immigration et l'état-nation à la recherche d'un modèle national, L'Harmattan, Paris.

Ingleby, D.

2012 "Ethnicity, Migration and the 'Social Determinants of Health' Agenda", Psychosocial Intervention, 21(3): 331-341.

Ingleby, D., M. Chimienti, P. Hatziprokopiou, et al.

2005 "The role of Health in Integration", in M. L. Fonseca and J. Malheiros (Eds.), Social Integration and Mobility: Education, Housing and Health, IMISCOE Cluster B5. State of the Art Report, Centro de Estudos Geograficos, Universidade de Lisboa, Unpublished manuscript, 101-137.

Ingleby, D., A. Krasnik, V. Lorant, et al. (Eds.)

2012 Health Inequalities and Risk Factors Among Migrants and Ethnic Minorities, COST Series on Health and Diversity, Vol. 1, Antwerp-Apeldoorn Garant Publishers.

OIM - International Organization for Migration

2016 Summary Report on the MIPEX Health Strand \& Country Reports, IOM Migration Research Series. August 2016. Available at: http://tinyurl.com/ju9fn43. (Accessed April 6, 2017).

Jayaweera, $\mathrm{H}$.

2010 "Health and access to health care of migrants in the UK", Better Health Briefing, no. 19, Race Equality Foundation, London.

2014 "Social Determinants of Migrants' Health", in B. Anderson and M. Keith (Eds), Migration: A COMPAS Anthology, COMPAS, Oxford.

Jessop, B. 1999

"The Changing Governance of Welfare: Recent Trends in its Primary Functions, Scale, and Modes of Coordination", Social Policy \& Administration, 33(4): 348-359.

Joppke, C. 
1999 "How immigration is changing citizenship: a comparative view", Ethnic and Racial Studies, 22(4): 629-652.

Lassetter J.H., L.C. Callister

2009 "The Impact of Migration on the Health of Voluntary Migrants in Western Societies: A Review of the Literature", Journal of Transcultural Nursing, 20(1): 93-104.

Lipsky M.

1980 Street-level bureaucracy. Dilemmas of the individual in public services, Russel Sage Foudation, New York.

Lynch, C., C. Roper

2011 "The Transit Phase of Migration: Circulation of Malaria and Its Multidrug-Resistant Forms in Africa", PLoS Med, 8(5): e1001040.

Marino, S.

2013 "Between old and new dilemmas: Describing trade unions' inclusive strategies", in A. Van Heelsum and B. Garcés-Mascareñas (Eds.), Migration and integration research: Filling in Penninx's heuristic model, Amsterdam University Press, Amsterdam: 50-61.

Marks, G., L. Hooghe, K. Blank

1996 "European Integration from the 1980s: State-Centric v. Multi-level Governance", Journal of Common Market Studies, 34(3): 341-378.

Marrow, H.B.

2012 "The power of local autonomy: expanding health care to unauthorized immigrants in San Francisco", Ethnic and Racial Studies, 35(1): 72-87.

McDaid D., S. Merkur, P. Mladovsky, et al.

2010 "Migration and Health in the European Union", Eurohealth, Vol. 16, No. 1/2010, LSE Health.

Merotta, V.

2011 "Welfare e politiche regionali: chi decide che cosa" [Welfare and regional policies: who decides what], in N. Pasini (Ed.), Confini irregolari. Cittadinanza sanitaria in prospettiva comparata e multilivello, FrancoAngeli, Milano: 183-198.

McKay, L., S. Macintyre, A. Ellaway

2003 Migration and Health: A Review of the International Literature, MRC Social \& Public Health Sciences Unit, University of Glascow, Glascow.

Mladovsky P.

2007 Migration and Health in the UE Report, Research Note, London School of Economics and Political Science and European Commission - Directorate-General "Employment, Social Affairs and Equal Opportunities" - Unit E1 - Social and Demographic Analysis.

Moreno Fuentes, F.J.

2015 "El puzzle de la exclusión sanitaria de los inmigrantes indocumentados en España", Anuario de la inmigración en España 2014, Edición 2015: 278-299.

Nazroo, J.Y.

2003 "The Structuring of Ethnic Inequalities in Health: Economic Position, Racial Discrimination, and Racism", American Journal of Public Health, 93(2): 277-284.

Pasini, N. (Ed.)

2011 Confini irregolari. Cittadinanza sanitaria in prospettiva comparata e multilivello [Irregular borders. Health citizenship in a comparative and multilevel perspective], FrancoAngeli, Milano.

Peiro, M-J., R. Benedict 
"Migrant health policy: The Portuguese and Spanish EU Presidencies", in McDaid D., S. Merkur, P. Mladovsky, et al. (Eds.), Migration and Health in the European Union, Eurohealth, Vol. 16, No. 1/2010, LSE Health, pp. 1-4.

Penninx, R., K. Kraal, M. Martiniello, et al. (Eds.)

2004 Citizenship in European Cities. Immigrants, Local Politics and Integration Policies, Ashgate, Aldershot.

Piattoni, S.

2010 The Theory of Multi-level Governance. Conceptual, Empirical, and Normative Challenges, Oxford University Press, Oxford.

Piore, M. J.

1979 Birds of Passage: Migrant Labor and Industrial Societies, Cambridge University Press, Cambridge.

Rechel, B., P. Mladovsky, D. Ingleby, et al.

2013 "Migration and health in an increasingly diverse Europe", The Lancet, 381: 1235-1245.

Saltman, R.B.

2008 "Decentralization, re-centralization and future European health policy", The European Journal of Public Health, 18(2): 104-106.

Schierup, C.U., P. Hansen, S. Castles

2006 Migration, Citizenship, and the European Welfare State: a European Dilemma, Oxford University Press, Oxford.

Scholten, P., H. Entzinger, R. Penninx, et al. (Eds.)

2015 Integrating Immigrants in Europe. Research-Policy Dialogues, IMISCOE-Springer Open.

Scuto, F.

2011 "L'assistenza sanitaria agli stranieri irregolari in Italia, in Spagna e in altri Stati europei" [Health care for irregular migrants in Italy, Spain and other European countries], in N. Pasini (Ed.), Confini irregolari. Cittadinanza sanitaria in prospettiva comparata e multilivello, FrancoAngeli, Milano: 129-166.

Steel, Z., B.J. Liddell, C.R. Bateman-Steel, et al.

2011 "Global Protection and the Health Impact of Migration Interception", PLoS Med, 8(6): e1001038.

Thomson, S., J. Figueras, T. Evetovits, et al.

2014 Economic crisis, health systems and health in Europe: impact and implications for policy, WHO Regional Office for Europe, Copenhagen.

Torres-Cantero, A.M., A.G. Miguel, C. Gallardo, et al.

2007 "Health care provision for illegal migrants: may health policy make a difference?", European Journal of Public Health, 17(5): 483-485.

van der Leun, J.

2003 Looking for loopholes. Processes of incorporation of illegal immigrants in the Netherlands, Amsterdam University Press, Amsterdam.

Vázquez, M.L., R. Terraza-Núñez, I. Vargas, et al.

2011 "Health policies for migrant populations in three European countries: England, Italy and Spain”, Health Policy, 101: 70-78.

Vertovec, S.

2007 "Super-diversity and its implications", Ethnic and Racial Studies, 30(6): 1024-1054.

Willen, S. S.

2012 "How is Health-Related Deservingness" Reckoned? Perspectives From Unauthorized im/Migrants in Tel Aviv", Social Science \& Medicine, 74: 812-821.

Zimmerman, C., L. Kiss, M. Hossain 
2011 "Migration and Health: A Framework for $21^{\text {st }}$ Century Policy-Making", PLoS Med, 8(5): e1001034-1/7.

Zincone, G.

1998 "Illegality, Enlightenment and Ambiguity: A Hot Italian Recipe", South European Society and Politics, 3(3): 45-82.

Zincone, G., R. Penninx, M. Borkert

2011

Migration Policymaking in Europe. The Dynamics of Actors and Contexts in Past and Present, Amsterdam University Press, Amsterdam. 